\title{
Leading Approaches to Conceptualizing the Quality of Higher Education
}

\author{
Valeriya Sizikova \\ Faculty of Social Work \\ Russian State Social University \\ Wilhelm Pieck str. 4, 129226 Moscow \\ Russian Federation \\ e-mail: Sizikovavv@rgsu.net \\ Anna Rybakova \\ Department of Social, general and clinical psychology \\ Russian State Social University \\ Wilhelm Pieck str. 4, 129226 Moscow \\ Russian Federation \\ e-mail: anya_rybakova@list.ru \\ Marina Vinogradova \\ Research Institute of Perspective Directions and Technologies \\ Russian State Social University \\ Wilhelm Pieck str. 4, 129226 Moscow \\ Russian Federation \\ e-mail: Vinogradovamv@rgsu.net
}

\begin{abstract}
This paper focuses on comparing the two leading approaches to conceptualizing of measuring quality in the system of higher education.

Specifically, we focus on the two main prevailing approaches, namely the continental one, and the Anglo-Saxon one. Both approaches are widely used, and both have their pros and cons. These approaches have radically different views on educational efficiency, thus dividing the concept and describing it from qualitative and quantitative perspectives.

Our results show that the most effective way for the educational organization to enhance the quality of its services would be to consider its activities from a variety of angles, scrutinizing financial resources, goals and objectives to better understand and rationalize the choice of this or that development strategy. We think that national educational system needs thorough comparative analysis but not copy-pasting practices if they are striving to be leading in the world educational arena.
\end{abstract}

\section{Introduction}

The shift in the system of higher education triggered curricula and program reforms in higher education that are not limited to teacher education and aim to bring higher education into line with basic education reforms and improve the relevance and quality of higher education around the world (Campbell 2019). The reforms allowed students enrolled in undergraduate degree programs at public higher education institutions free-of-charge tuition and provided grants to disadvantaged elementary students throughout the higher education system (Egorychev et al. 2016).

There are many examples of these changes all across the globe. In 2016, the Higher Education Commission established a policy framework and strategies for the internationalization of higher education in the Philippines (Adeyemo and Sehoole 2016). Of course, there are limits to this progress, for example, in terms of available tertiary education and the number of students who receive grades for higher education, and how quality is defined in the context of the Philippines. Delivering high quality higher education was a constant problem not only in the Philippines and, in times of higher education consolidation, with the expansion of the public and private higher education sector and given the discrepancy between graduates, a particular challenge to learning and the demands of industry. Increased cooperation between the various stakeholders, including industry, in the reshaping of the higher education curriculum, the introduction of international benchmarking and the increasing internationalization of higher education (both abroad and domestically) should be part of the quality problem (Sam 2018). Experts and others have their own perspective and measure the quality of higher education based on various parameters within their own framework.

In India, graduates are viewed as products whose career opportunities depend on the quality of education they seek. To ensure the level of quality, we have two broad parameters: the accreditation of academic 
programs by government agencies and others and the classification of academic institutions by private professional agencies on the basis of given parameters (Altbach 2015; Aithal and Suresh Kumar 2016). Another approach to assessing quality is to ask people whether they have benefited from the college or the university. The College Results Instrument (CRI), developed by the National Center for Postsecondary be presented ten different scenarios five years after graduation. The instrument's design helps potential students make better informed choices amongthe various colleges and universities they can apply for. Employees at the international sites should have the opportunity to contribute fully and equally to the operation of quality assurance systems and processes in their school.

All in all, it seems that management of the international higher education institutions should be consulted on specific quality assurance arrangements at school level and obtained their consent, provided that they affect the functioning of these institutions (Reda 2017; Strielkowski et al. 2018). When the same programs and modules are offered on more than one campus the headmaster is responsible for communicating and implementing all changes to this provision and how they are delivered across campus.

Nowadays, it is widely acknowledged that in addition to the scientific results, the practical wisdom of the practitioners of their specific practice communities is important in interpreting scientific knowledge and establishing a necessary link to effective policy or program design. Certain institutional know-how becomes an important attribute of maintaining and measuring the quality in higher education (Strielkowski 2018).

Nevertheless, annual ranking of results and world reports on achieving various scientific and publication indicators can also be irretrievably flawed as an assessment of the quality of higher education. They focuse heavily on input and reputation measures, uses retention as the only measure of outcome, and does not make any effort to evaluate value added.

\section{Universities choice of development strategies}

Higher education should meet the interests of students and society in general. While the basic function of higher education can be considered responsible for passing on knowledge to the younger generation and promoting basic knowledge, the fact is that higher education today interacts with many other areas of public policy.

In addition to education and research, higher education interacts with areas such as health, industry, culture, territorial development and the labor market. To meet this public responsibility, they have in the past received generous state resources and, at least in some countries, an adequate level of institutional and academic autonomy.

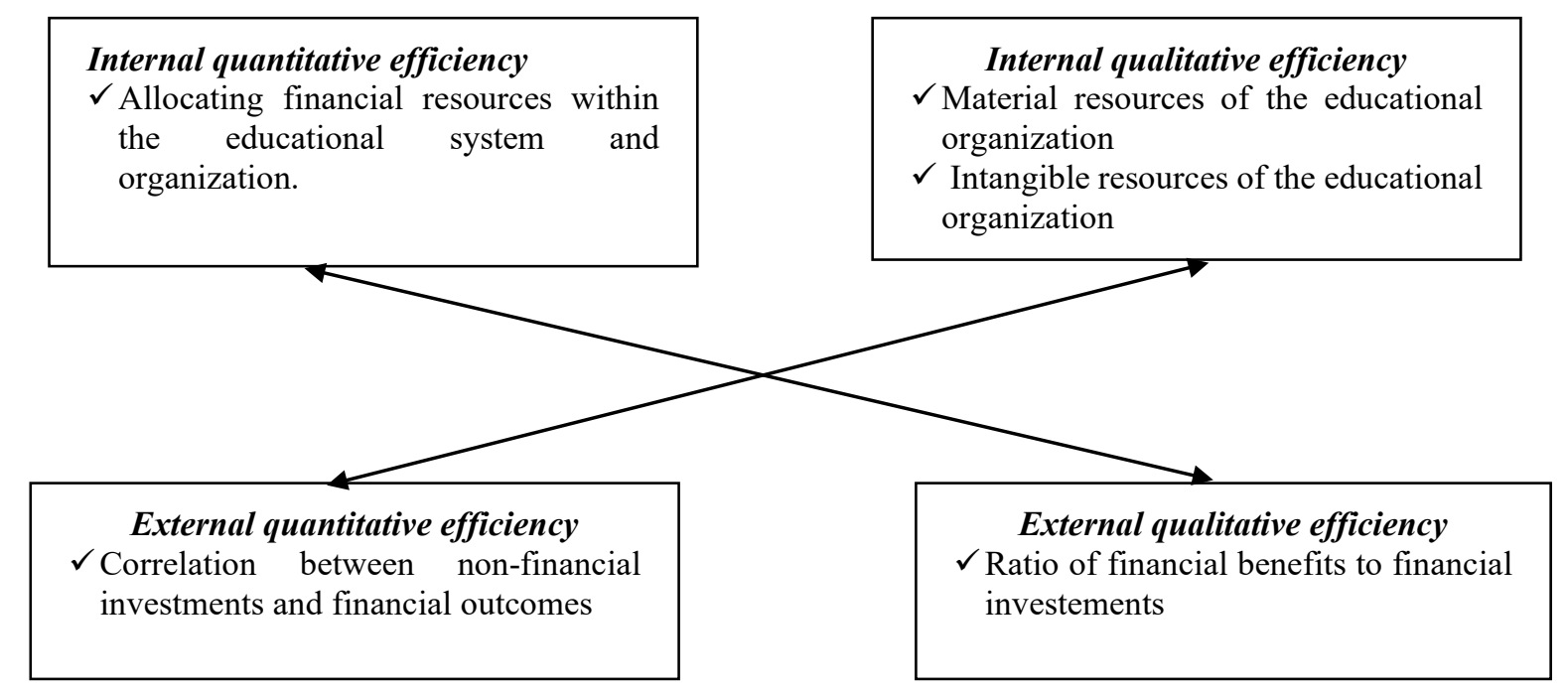

Fig. 1. The structural and logical diagram of an effective educational organization.

Source: Own results

Nowadays, the basic functions of the universities undergo a process of change. Higher education is not only expected to provide excellent education and research, but also to deliver the results in ways, quantities and forms that are relevant to the production process and to the formation of the knowledge society. As the university program took root, others saw the potential for similarly structured programs in school administration, educational entrepreneurship, medicaleducation and senior learning officers. A focus on strategy should help institutions to experiment and take initiative, to ask questions and create synergies, and to advance institutions in 
often unknown and unrecognizable environments (Gulicheva and Osipova 2017). By defining different types of discussions as part of strategic planning efforts, one would be able to achieve different and more favorable results from these processes. The plan relates to a) specific (community and system) changes that need to be targeted, and b) the specific steps needed to bring about change in all relevant sectors or parts of the community. The key aspects of the intervention or the (community and system) changes that are to be targeted are listed in the action plans.

For example, one of the strategies in a program whose job it is to increase youth's interest in politics might be to bring students closer to the electoral system. Action steps are developed for each component of the intervention or the (communityand system) changes that are to be searched.

We will consider the most important indicators that are relevant to determining the quantitative and qualitative efficiency of a HEI by using the structural-logical diagram that describes the relationship between all indicators defining the educational organization as a system with a high or low level of efficiency (Figure 1 above)

An analysis within each of the quadrants will help with the choice of a development strategy for the university. As an example, the analysis of internal quantitative efficiency, which assumes understanding the distribution of financial flows within an organization, can build a policy, outline the goals and objectives of an educational organization. An alternative outline for building a strategy can rest on allocating available resources in such a way that they bring the maximum possible result. In case the quality of the educational program (nonfinancial investments) guarantees a high salary for its graduates (financial gain), then, using an analysis of the economic effect of investments, the educational organization can vision its development in increasing its competitiveness by improving the quality of educational programs offered. Thus, the efficiency of the educational organization should be assessed in terms of the effectiveness of the implementation of the unique mission defined by the educational organization based on the analysis of indicators described within the previously mentioned quadrants. In the context of changing the paradigm of higher educational system and conceptualizing a new mission of the educational organization, it is worth mentioning the concept of an entrepreneurial university. The concept of entrepreneurial university is not new and appeared at the end of the eighteenth century, when there had been tlaks about taking risks when buying and selling goods. These were the times, when entrepreneurial schools started to merge. Scholars were trying to understand and describe the psychological and social sources of entrepreneurship.

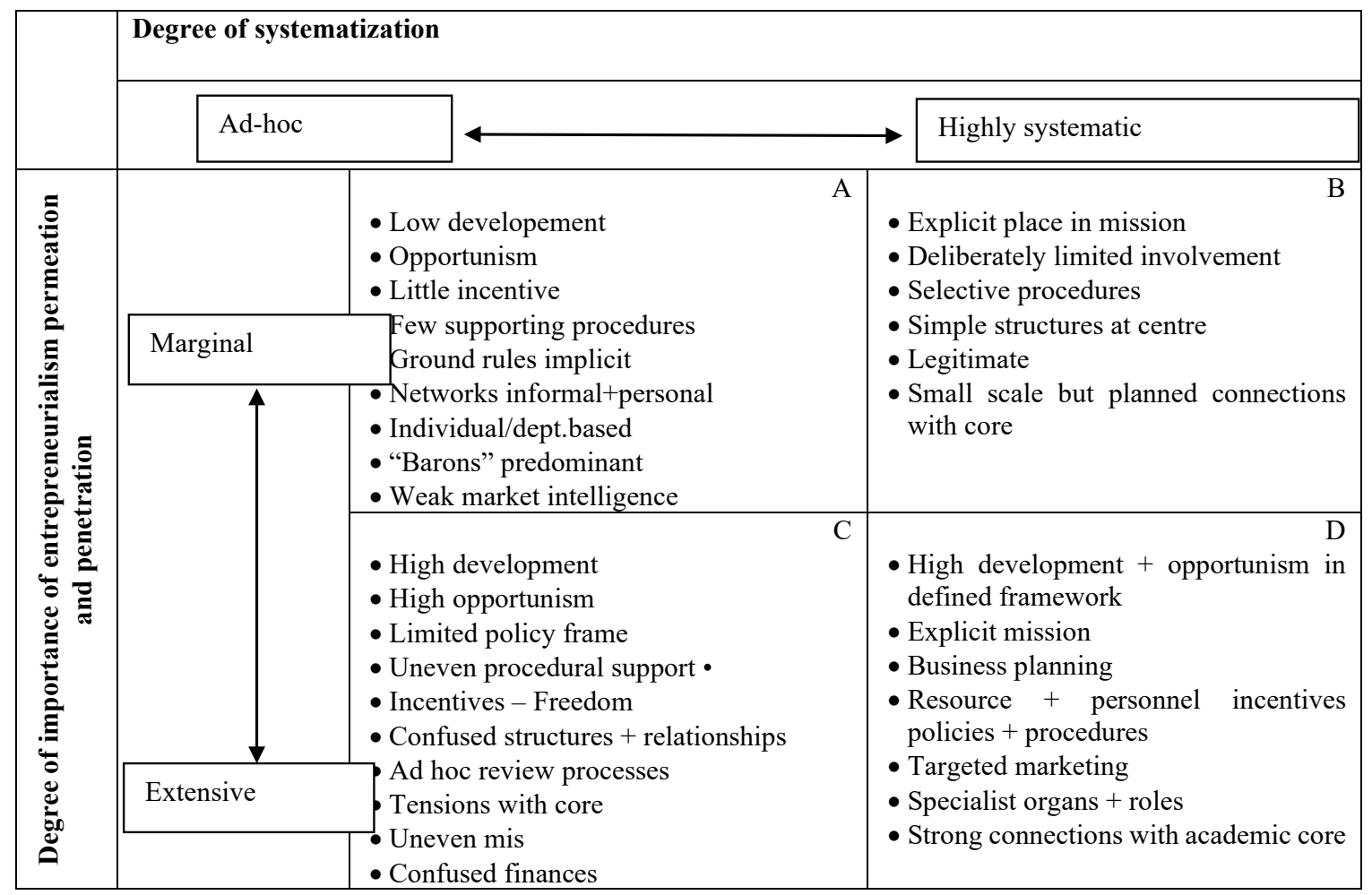

Fig. 2. Model of entrepreneurial culture of an educational organization Source: Adapted from Davies (2001) 
Harvard Business School professor Howard Stevenson (Stevenson and Jarillo-Mossi 1990) made the greatest contribution to describing the phenomenon of entrepreneurship. According to Stevenson, "Entrepreneurship is a pursuit of an opportunity beyond the resources currently controlled". First of all, Stevenson defined entrepreneurship as a management process, believing that the promotion of entrepreneurial behavior and the development of an entrepreneurial culture can be a good basis for creating a long-term and sustainable economy. Stevenson was able to prove that conducting entrepreneurial practice is just as important, if not more so, for an already established and functioning company, as well as for newcomers.

Later, other scholars began talking about the entrepreneurial culture of the educational organization. For example, in his work "The Emergence of an Entrepreneurial Culture in European Universities", Professor John Davies (2001) describes a culture that is not universal, but inherent in many European universities. A distinctive feature of the existing culture of the educational organization is the extremely low corporate identity, as well as the trend of non-interference in the life of the university. Culture is often highly individualistic and autonomous, which means detachment, isolation, defensive behavior and the denial of the need to develop a comprehensive strategy at the faculty or university level. The culture is predominantly friendly, non-threatening and reliable, however, personal and group responsibility, from the point of view of the implementation of internal processes, is low. There is a reluctance on the part of university faculty to confront external problems, which is sometimes interpreted as consensus, as a result of which norms and regulations acquire particular weight, especially in systems with a strong administrative spirit.

Traditionally, educational institutions have a limited forecasting horizon, development goals and strategies are ambiguous, inaccurate, and are not associated with the "toolkit of change". That is why the adaptation of any political decision is a painful and slow process; the bureaucracy is the dominant norm. Entrepreneurial culture of an educational organization is also important (see Fig. 2 above).

Since the end of the twentieth century, a number of factors have destabilized the status quo described above in European universities. Reduction in state funding served as an imperative to attract various financial sources; pressure from the state and the industrial sector aimed at shifting to applied research in education that meets the needs of public sector organizations; promotion of lifelong learning; globalization of education and new opportunities that have occurred thanks to the revolution in the information space and knowledge society.

Since the end of the 1980s of the twentieth century, Western European universities have carried out a number of structural changes, which made it possible to respond quickly to the challenges of society. Over the years, Europe has developed an amazing ability to conduct activities that are different from traditional academic research and knowledge transfer. The prevailing culture implied researching on the order of production enterprises, consulting, technology transfer, continuing education, advanced training in various forms, the influx of a large number of foreign students, the promotion of educational services abroad through the opening of foreign branches, signing franchise contracts, e-education and the commercialization of physical university property - dormitories and sports facilities. The volume and scale of these transformations may vary depending on the characteristics of the systems in which educational organizations exist. European universities were gradually able to form a culture, later called entrepreneurial (Guo et al. 2019; Guerrero and Urbano 2017).

The concept of entrepreneurship is associated with the awareness of financial processes, the ability of an educational organization and all its employees to conduct a financial analysis of available opportunities make a surplus that can later be invested in development, or will cover the deficit caused by a reduction in state financial support, admission and other circumstances. As the long-standing practice of European educational organizations has shown, entrepreneurship is inherent in those systems in which a reduction in funding has destabilized institutional security. The most important aspects that are important in building an entrepreneurial culture in an educational organization were preposed by Davis (2001) and described as a model that allows us to attribute the educational organization to a system with a high or low level of systematization and significance of entrepreneurial cunlture (Figure 2).

This model allows the educational organization to determine its position in one of the proposed quadrants. Indicators of the characteristic features of each subtype are registered within each quadrant.

However, analysis of each faculty or department in terms of these indicators can be convenient and useful, especially in the case of a decentralized and differentiated approach to solving problems. The proposed model allows educational organizations to determine their position in one of the quadrants. Further, based on the analysis, the educational organization should decide for itself the question: in what direction will the development go? If the organization is located in quadrant $\mathrm{A}$, is it worth it to strive for quadrant $\mathrm{C}$, or is it enough to systematize their internal procedures and find the niche in quadrant B? An analysis of the indicators of the proposed models allows us to conclude that, regardless of the chosen model, the implementation of the university's strategy and its unique mission will be crucial in determining the efficiency. 


\section{Continental and Anglo-Saxon systems of higher education}

The system of higher education distinguishes between two main approaches to quality policy issues: continental, where external evaluation prevails, based on verification of graduates' compliance with the requirements of the national and regional economies; and Anglo-Saxon, which increasingly recognizes the independence and autonomy of universities in the choice of development strategies and forms of control.

Each of the approaches interprets the concept of efficiency in its own way, which led to its differentiation into quantitative and qualitative (efficiency vs. effectiveness). Differentiation of these concepts predetermined a change in the paradigm of education. The ability to carry out activities and achieve results with the least resources available, effort, time and finances does not contribute to the achievement of a mission, goals or objectives. Counting hours of class work, the age of students and their entry scores are less important in solving social problems that higher education has to solve.

Eric A. Hanushek, a professor at Stanford University, defines qualitative effectiveness as the result of a special analysis, for example, verification of educational effectiveness or reports on institutional effectiveness, which reflects the quality of achievement of a specific educational goal or the degree to which a higher educational institution can achieve compliance with specific requirements. As the main measure of the success of a program or university, clear indicators, significant information and supporting documents that best describe the effectiveness of the institution in relation to student learning and achievement should be collected using a variety of different procedures: verification, monitoring, visits by an expert commission, etc. (Klofsten et al. 2019; Etzkowitz 2017) Qualitative effectiveness shows how much the invested resources had a positive effect on the achievement of results and what this effect turned out to be. Qualitative effectiveness is not related to the use and cost of funds. However, there is often a confusion of concepts, which leads to the fact that large financial investments in education do not give the desired effect (Tarasova et al. 2019; Brem and Radziwon 2017; Sánchez-Barrioluengo and Benneworth 2019).

The concept of the effectiveness of educational activities is associated with the concept of quality. Many countried-members of the European Higher Education Area (EHEA) define quality as a dynamic, multidimensional, multi-level concept, covering the contextual content of the education model, goals, objectives and mission of higher education institutions, as well as the specific standards of each individual system, university, program or discipline, thus recognizing the relevance of the mission, goals and objectives of educational organizations to form a culture of quality in the educational organization (Schindler et al. 2015). This definition includes standards inherent in the education systems of different countries and universities but leaves the right for the educational organization to decide independently on a development strategy. Moreover, the concept of a quality culture is being introduced in a number of educational organizations, which supposes freedom of self-determination (Gilmore et al. 2018; Centobelli et al. 2019). The focus is on determining the goals and mission of the educational organization without checking for compliance with external expectations (standards or guidelines).

In Japan, there are at least three ways to control college entry: the ao method (with credentials for students who have performed well and have shown dedication and skill in sports or other extracurricular activities), a centralized multiple-choice exam, which is known as the National Center Test for University Admissions and Admissions Exams, which is set by each university. For public universities, the center test is often used as the first filter stage todetermine the suitability for the more difficult exams that have been set by each individual university.

In the Anglo-Saxon system that has been shaped by the educational system of British Empire, schools were established in collaboration with hospitals or poorhouses that had the same facilities and facilities (Lowndes 1956). In 1422, Archbishop Chichele set up a college in Higham Ferrers, his birthplace in Northamptonshire, and incorporated a poorhouse and an existing high school (Leach 1915).

Many of the British endowment schools of that time offered free lessons, and some were aimed specifically at less wealthy people. Regarding the poorest, they were not entitled to free education, but they needed a lot of encouragement or ambition to use them. As the 15th century came to an end and the sixteenth began, rising prosperity, a calmer political climate, and a growing population led to greater investment in education through private philanthropy. Access to these new schools was not limited to one place, but on a national basis. They increasingly resorted to a single social class and combined the educational methods of high schools and the social training of the Knight system. The deed of incorporation was granted in 1382, construction began in 1387 and the first scholars entered the school in 1394. At the same time, Wykeham also founded New College Oxford to train his Winchester students. Since 1988, the subjects to be taught at public schools have been laid down in the national curriculum, which also sets the standards to be achieved (New College 2019).

Nowadays, children have to study the core subjects of English, mathematics and science aswell as the basic subjects of technology, geography, history, art, music and sports. The national curriculum does not apply in Scotland, and schools are free to decide how much time they devote to each subject. They pass examinations for the General Certificate of Secondary Education (GCSE) or the Scottish Certificate of Education. At first glance, 
this seems to be a fairly broad curriculum, but it should not be forgotten that everything was focused on the church: scripture was the central theme, and rhetoric teaching was primarily a study of word forms in the Bible. Grammar was Latin, and versification was in the same context, although it sometimesreferred to poetry in the vernacular. Music and law were professional studies of church services and administration, and natural history, in contrast to Aristotelians, was literary and anecdotal. In the 15th century, various groups began to set up education systems mainly related to occupations or occupations.

In a sense, all medieval education was technically and professionally geared to a particular job or function, and apprenticeship training was the form it usually took (Todd and Orme 1990). Such programs gradually spread to provincial towns, and by the 15th century, the new entrants were expected to have adequate educational standards. Skills (dius) was abolished after only two years of existence and the responsibility transferred to a new department for Business, Innovation and Skills (BIS). The name was changed four times and finally the higher education merged with employment, skills and business. What these terminological changes reflect is that successive governments, whether they were Labor or Conservative governments, shared the view that the UK higher education system should play a crucial role in the country's economy. In order to achieve these goals, the basic structures of national systems need to be unified.

\section{Conclusions}

In general, establishing the best practices of measuring quality and setting up the quality assurance in higher education is subjected to many factors, such as institutional, regional, cultural, as well as social and economic. The initiative places a particular emphasis on the transition to university life and encourages students to focus on developing basic social skills that enhance their chances of success.

Each system of quality assurance in higher education is facing the problem of developing new approaches and mechanisms that would consider and take into account information about the quality and effectiveness of educational activities during state accreditation and / or monitoring of educational activities.

However, the governements should keep in mind that it is impossible to borrow someone else's national quality assessment system, just as it is impossible to take the accreditation system of another country in its finished form and apply in a different educational environment with its own background. The development of the own system, taking into account the contextual features of the country, can help strengthen the quality of national higher education in the context of international integrative processes, increase usefulness and limit the potential shortcomings of the internationalization of higher education. In addition to the practices of countries with the highest rates of innovation index, it is advisable to analyze countries that have positive experience transferring part of the authority of state bodies to independent accreditation agencies (Sidrat and Frikha 2018).

The new measuring system may be characterized by voluntary procedures by non-governmental accreditation agencies. The parameters of the new accreditation system will be the development of internal quality assurance mechanisms in the educational organization, the assessment of the self-examination procedure and the implementation of recommendations.

Thus, information on educational and quality assurance systems of world-leading countries is a necessary tool for analyzing existing trends in the development of quality assurance systems, using positive experience and studying problem areas both in a single educational organization and in the higher education system as a whole, and can serve as a useful development tool, improving quality and performance indicators of the higher education system of a country.

\section{References}

Adeyemo KS, Sehoole C (2016) Higher education and the challenges of skills production in the Philippines. South African Journal of Higher Education 29(2). doi: 10.20853/29-2-475

Altbach P (2015) Indian Higher Education Internationalization. International Higher Education 53. doi: 10.6017/ihe.2008.53.8047

Brem A, Radziwon A (2017) Efficient Triple Helix collaboration fostering local niche innovation projects - A case from Denmark. Technological Forecasting and Social Change.123:130-141. doi:10.1016/j.techfore.2017.01.002

Campbell AC (2019) Exploring the Relationship of Home Country Government Reforms and the Choices of International Higher Education Scholarship Program Participants. European Education 51(2):147-163. doi: $10.1080 / 10564934.2019 .1569470$ 
Centobelli P, Cerchione R, Esposito E, Shashi (2019) Exploration and exploitation in the development of more entrepreneurial universities: A twisting learning path model of ambidexterity. Technological Forecasting and Social Change. 141:172-194. doi:10.1016/j.techfore.2018.10.014

Davies JL (2001) The Emergence of Entrepreneurial Cultures in European Universities. Higher Education Management. 13(2):25-43

Egorychev AM, Mardakhaev LV, Rybakova AI, Fomina SN, Sizikova VV (2016) Society and education in the early of XXI century: Integration of tradition and innovation. Journal of Advanced Research in Law and Economics 5(2):82-91

Etzkowitz H (2017) Innovation Lodestar: The entrepreneurial university in a stellar knowledge firmament. Technological Forecasting and Social Change. 123:122-129. doi:10.1016/j.techfore.2016.04.026

Gilmore A, McAuley A, Miles MP, Pattinson H (2018) Four questions of entrepreneurial marketing education: Perspectives of university educators. Journal of Business Research. doi: 10.1016/j.jbusres.2018.12.016

Guerrero M, Urbano D (2017) The impact of Triple Helix agents on entrepreneurial innovations' performance: An inside look at enterprises located in an emerging economy. Technological Forecasting and Social Change. 119:294-309. doi:10.1016/j.techfore.2016.06.015

Gulicheva E, Osipova M (2017) Program-target method of pricing for international educational services. Czech Journal of Social Sciences, Business and Economics 6(1):21-27. doi: 10.24984/cjssbe.2017.6.1.3

Guo F, Restubog SLD, Cui L, Zou B, Choi Y (2019) What determines the entrepreneurial success of academics? Navigating multiple social identities in the hybrid career of academic entrepreneurs. Journal of Vocational Behavior. 112:241-254. doi:10.1016/j.jvb.2019.03.003

Klofsten M, Fayolle A, Guerrero M, Mian S, Urbano D, Wright M (2019) The entrepreneurial university as driver for economic growth and social change - Key strategic challenges. Technological Forecasting and Social Change. 141:149-158. doi:10.1016/j.techfore.2018.12.004

Leach AF (1915) The Schools of Medieval England. http://www.educationengland.org.uk/documents/leach/leach1915.html Accessed on 28 November 2019

Lowndes G (1956) The British Educational System. British Journal of Educational Studies 4(2):193. doi: $10.2307 / 3118994$

New College (2019) The history of the New College. https://www.new.ox.ac.uk/history-new-college. Accessed on 29 November 2019

Reda NW (2017) Balanced scorecard in higher education institutions. Quality Assurance in Education 25(4):489-499. doi: 10.1108/qae-09-2015-0038

Sam V (2018) Overeducation Among Graduates in Developing Countries: What Impact on Economic Growth? Journal of Eurasian Economic Dialogue 3(6):1-19

Sánchez-Barrioluengo M, Benneworth P (2019) Is the entrepreneurial university also regionally engaged? Analysing the influence of university's structural configuration on third mission performance. Technological Forecasting and Social Change. 141:206-218. doi:10.1016/j.techfore.2018.10.017

Schindler L, Puls-Elvidge S, Welzant H, Crawford L (2015). Definitions of quality in higher education: A synthesis of the literature. Higher Learning Research Communications. 5(3):3-13. doi:10.18870/hlrc.v5i3.244

Sidrat S, Frikha MA (2018) Impact of the qualities of the manager and type of university on the development of the entrepreneurial university. The Journal of High Technology Management Research. 29(1):27-34. doi:10.1016/j.hitech.2018.04.003

Stevenson HH and Jarillo-Mossi JC (1990). A Paradigm of Entrepreneurship: Entrepreneurial Management. Strategic Management Journal 11(4): 17-27

Strielkowski W (2018) A postdoc's purpose. Science 360(6384):27-27. doi: 10.1126/science.aat6008

Strielkowski W, Kiseleva L, Popova E (2018) Factors determining the quality of university education: students' views. Integration of Education 22(2):220-236. doi: 10.15507/1991-9468.091.022.201802.220-236

Tarasova AN, Korneeva EN, Krayneva RK, Gudkova SA (2019) Pitfalls and Drawbacks in Engineering Education in Russia. Journal of Applied Engineering Sciences. 17:43-51. doi: 10.5937/jaes17-19097 
Todd BJ, Orme N (1990) Education and Society in Medieval and Renaissance England. History of Education Quarterly 30(3):416. doi: 10.2307/368707 